\title{
IKAROS expression profiles characterize different autoimmune diseases
}

\author{
Leydy Katherin Duque Suárez ${ }^{1}$, Gerardo Quintana López ${ }^{2,3}$, Paola Ximena Coral Alvarado ${ }^{2,3}$, \\ Paul Alejandro Méndez Patarroyo ${ }^{2,3}$, Helena Groot deRestrepo ${ }^{1}$ and Valeriano López-Segura ${ }^{1,2^{*}}$ (D)
}

\begin{abstract}
Background: Autoimmune diseases are syndromes characterized by an immune response against self-antigens. They are complex pathologies associated with a variety of genetic determinants, but these genes cannot fully explain the aetiology of autoimmune disorders. Ikaros is a transcription factor that plays a major role in lymphoid differentiation.
\end{abstract}

Methods: In this study, we characterized the expression profiles of Ikaros isoforms by quantifying the interexonic regions of patients diagnosed with Sjögren's syndrome, systemic lupus erythaematosus, systemic sclerosis and rheumatoid arthritis in RNA extracted from peripheral blood. REST software was used for relative quantification and Hierarchical clustering analysis was performed using Cluster and TreeView.

Results: The expression of Ikaros was altered in all diseases examined. Significant differences were found in all of the interexonic regions between the comparison groups. Decreased expression of the IE3-4, 4-5 and 5-6 regions in all of the autoimmune pathologies was associated with the presence of dominant negative isoforms. Differences in the expression of several exons in rheumatoid arthritis and systemic lupus erythaematosus indicated the presence of different isoforms, which could serve as biomarkers for these diseases.

Conclusion: This study is the first conducted in Latinamerica that sought to determine the relationship between Ikaros and autoimmune diseases and is the first description of Ikaros in patients with rheumatoid arthritis, Sjögren's syndrome and systemic sclerosis. Furthermore, we confirmed that Ikaros expression is altered in systemic lupus erythaematosus.

Keywords: Autoimmune diseases, Ikaros transcription factor, Splice variants, Dominant negative isoforms, qRT-PCR

\section{Significance \& innovation}

1. It is a pioneering study in relating the Ikaros family to autoimmune diseases.

2. For the first time the Ikaros gene is used to discriminate autoimmune diseases.

3. We describe a simple method that can help diagnose and monitor diseases.

\section{Background}

Autoimmune diseases (AIDs) are clinical syndromes caused by the loss of immunological tolerance that are characterized by the production of antibodies against self-antigens,

\footnotetext{
* Correspondence: v.lopez22@uniandes.edu.co

${ }^{1}$ Human Genetics Laboratory, Universidad de los Andes, Bogotá, Colombia

${ }^{2}$ School of Medicine, Universidad de los Andes, Cra. 1, No18 A 10, Building i,

Office 112, Bogotá, Colombia

Full list of author information is available at the end of the article
}

which generate tissue damage [1]. Overall, these diseases occur in 3 to $5 \%$ of the population, with an incidence of 90 cases per 100,000 people. They occur more frequently in women and may appear at any life stage [2]. In the present study, we analysed the expression of Ikaros, an important regulator of immune function, in four systemic diseases: rheumatoid arthritis (RA), systemic lupus erythaematosus (SLE), Sjögren's syndrome (SS) and systemic sclerosis (SSc).

AIDs are complex diseases with environmental and polygenic components. Environmental factors have been associated with the development of AID, such as smoking; drugs; exposure to UV radiation, different chemicals or infectious agents; and hormonal factors [3-6]. The most important genes associated with these diseases are PTPN22, CTLA4, TRAF1 -C5, PAD4, and STAT4 as well as genes

(C) The Author(s). 2018 Open Access This article is distributed under the terms of the Creative Commons Attribution 4.0 International License (http://creativecommons.org/licenses/by/4.0/), which permits unrestricted use, distribution, and reproduction in any medium, provided you give appropriate credit to the original author(s) and the source, provide a link to the Creative Commons license, and indicate if changes were made. The Creative Commons Public Domain Dedication waiver (http://creativecommons.org/publicdomain/zero/1.0/) applies to the data made available in this article, unless otherwise stated. 
coding for HLA DR [7-9]. However, these genes cannot explain the aetiology of all types of AID.

Ikaros is the key member of a family of transcription factors involved in lymphopoiesis. Ikaros is characterized by two domains comprising highly conserved zinc fingers [10]. The first domain binds to specific DNA sequences depending on how many zinc fingers contains by alternative splicing [11]. The high level of alternative splicing can generate multiple isoforms from each gene, including isoforms that arise from non-canonical splicing due to insertions and deletions [12-14]. Some of these, such as Ik6, act as dominant negative (DN) isoforms and have been associated with certain haematological pathologies [15-17]. These isoforms can kidnap functional isoforms (Ik1, Ik2, Ik3, etc.) in the cytoplasm, inhibiting their action on its target genes and thus restricting their role as transcription factors [18].

Ikaros plays a fundamental role in the differentiation of haematopoietic stem cells into lymphoid lineages [19], but, the relationships between the presence of dominant negative isoforms and different types of haematological neoplasias have been described, suggesting that Ikaros plays an important role as a tumour supressor [20-22]. The function of Ikaros in proper lymphocyte maturation and interferon production [23-25] clearly indicate that it could play an important role in the origin of autoimmune diseases, as it does in the development of leukaemias. However, members of the Ikaros transcription factor family are not currently used as susceptibility and/or diagnostic markers because of their numerous isoforms and expression level variations as well as the technical difficulties associated with obtaining quantitative data. The correlations found in different studies between the overexpression of dominant negative isoforms and different types of leukaemias were determined using RT-PCR, agarose gel electrophoresis and subsequent sequencing of fragments of interest [15, 16, 26-28]. Although these kinds of studies provide information about the expression of specific isoforms, they cannot elucidate complete gene expression patterns for different types of diseases [29].

Given the technical inability to obtain real quantitative data for the expression levels of all Ikaros isoforms, a different protocol was used to characterize the expression profile of each interexon based on qRT-PCR. Though this method does not provide accurate information about each isoform, qualitative changes in gene expression can be observed and associated with a profile, which can then be linked to a disease. The use of this technique in a previous study allowed different types of haematological malignancies to be distinguished, demonstrating that the expression of Ikaros is disease-specific [21].

In this study, we characterized the expression profiles of the exons of the Ikaros gene in Whole blood samples from patients diagnosed with Sjögren's syndrome, systemic lupus erythaematosus, systemic sclerosis and rheumatoid arthritis by qRT-PCR. This method could be of great diagnostic and monitoring value for these diseases.

\section{Material and methods Individuals and samples}

One hundred eighty individuals of both sexes who were diagnosed in the Rheumatology Department at the Hospital Fundación Santa Fe de Bogotá with rheumatoid arthritis (RA; 47), systemic lupus erythaematosus (SLE; 26), systemic sclerosis (SSc; 43) or Sjögren's syndrome (SS; 25) and were in the active stage of their disease were included in this study. Thirty-nine healthy controls were established in the same age range (Table 1). We excluded patients who had undergone organ transplantation (including bone marrow), had any type of cancer, were pregnant or were diagnosed with other autoimmune diseases.

\section{RNA extraction and CDNA synthesis}

Peripheral blood samples were taken after each patient signed the informed consent form approved by the ethics committees at the Universidad de los Andes (Act No. 176 approved under resolution No. 008430 of 1993 of the Ministry of Health). RNA extraction was performed using whole blood, following the protocol of the manufacturer for the TRIzol reagent (Invitrogen). RNA quality and integrity were analysed through quantification by spectrophotometry. Only samples with $\mathrm{OD}_{260} / \mathrm{OD}_{280}$ ratios between 1.8-2.0 were used for reverse transcription. cDNA was synthesized from $1 \mu \mathrm{g}$ of RNA following the protocol of the ImProm-II Reverse Transcription System (Promega). cDNA was quantified spectrophotometrically.

\section{Quantitative RT-PCR (qRT-PCR)}

Several Ikaros isoforms that were previously cloned into plasmids and digested were used to standardize the qRT-PCR method and to construct standard curves. Appropriate efficiencies in the range of 90 $110 \%\left(R^{2}=0.996\right)$ were obtained using serial dilutions (25, 50, 100 and $200 \mathrm{ng}$ ) of these cloned isoforms to confirm the reproducibility of our data.

Table 1 Patients and controls included in this study

\begin{tabular}{llllll}
\hline & Controls & RA & SLE & SS & SSC \\
\hline$N$ & 39 & 47 & 26 & 25 & 43 \\
Age (years) & 46.1 & 55.1 & 39.7 & 57.9 & 51.9 \\
& $(22-79)$ & $(24-77)$ & $(19-63)$ & $(33-80)$ & $(20-80)$ \\
Female & 23 & 40 & 23 & 25 & 41 \\
& $(59 \%)$ & $(85.1 \%)$ & $(88.5 \%)$ & $(100 \%)$ & $(95.3 \%)$ \\
\hline
\end{tabular}

$R A$ rheumatoid arthritis, SSC systemic sclerosis, SLE systemic lupus erythaematosus, SS Sjögren's syndrome 
The efficiency of the qRT-PCR method was also monitored in every experiment using standard curves from the different PCRs randomly. This efficiency and the normalized gene values were calculated for each of the qRT-PCR assemblies. To assess the specificity of the primers and the qRT-PCR method, we studied the melting curve of each amplicon with cloned material, which proved that the qRT-PCR was specific (data not shown) [30, 31]. The glyceraldehyde 3-phosphate dehydrogenase gene $(G A P D H)$ was used for normalization of the qRT-PCR data. The mean threshold cycle (Ct) for GAPDH was $27.42 \pm 1.35$, very robust data for an internal control.

The PCRs were performed with primers designed in interexonic region $2-3\left(2 \mathrm{~F}, 5^{\prime}\right.$ - GATCCCCGAGGACC TCTC-3', and 3R, 5' - CGTAAATCCTCCGCACATT C-3'), interexon 3-4 (3F, 5' - TGTGATATCTGTGGGAT CATTTG-3', and 4R, 5' - GGAATGCAGCTTGATGTG C-3'), interexon 4-5 (4F, 5' - CCCTTCAAATGCCACCT CT-3', and 5R, 5' - GCAGCGCTCTTTATGTTCCT-3'), interexon 5-6 (5F, 5' - GGCGACGTTACTTGCTAGT CT-3', and 6R, 5'-GGCGACGTTACTTGCTAGTCT-3') and interexon 6-7 (6F, 5'-AGCAAGTAACGTCGCCAAA C-3', and 7R, 5'- CGTTGTTGATGGCTTGGTC-3') (Fig. 1). We designed forward primers at the end and reverse primers at the beginning of each exon. Interexon 12 was not considered because no splicing variants have been reported in this region. The primers were designed based on the Ikaros sequence BT009836.1 obtained from the National Center for Biotechnology Information (NCBI) GenBank database. Some of the primer parameters, such as the primer affinity for the target sequence, annealing temperature and specificity between pairs, were assessed using the web program IDT SciTools PrimerQuest SM (www.idtdna.com).

The experiments were conducted using a 7500 Fast Real-Time PCR instrument (Applied Biosystems). Detection of the amplicons was evaluated with the Power SYBR $^{\circ}$ Green PCR Master Mix (Applied Biosystems). The standard protocol was conducted according to the manufacturer instructions as follows: activation of the enzyme at $95^{\circ} \mathrm{C}$ for $10 \mathrm{~min}$ and 40 cycles of denaturation at $95^{\circ} \mathrm{C}$ for $15 \mathrm{~s}$ and annealing and extension at $55^{\circ} \mathrm{C}$ for $1 \mathrm{~min}$. The melting curve was standardized with the following parameters: temperature range of $65-95^{\circ} \mathrm{C}$ with temperature increases in $0.5{ }^{\circ} \mathrm{C}$ increments and measurements in 3-min intervals.

\section{Statistical analysis}

Relative quantitation and standardization was performed with the software REST 2009 version 2.0.13, which is based on the $\Delta \Delta \mathrm{Ct}$ method and incorporates the PCR efficiency information [32,33]. The patient samples were paired with controls by sex and age range. Statistical tests were conducted using the " $R$ " statistical package version 3.3.1. The assessment of data normality was determined with the Shapiro-Wilk test, followed by the nonparametric methods of Kruskal-Wallis and Dunn multiple comparison tests for expression level comparisons. The Wilcoxon test was used to compare the expression levels with patient sex. Interexon expression differences were determined to be significant at $p$-values less than 0.05 .

For the hierarchical clustering analysis, a logarithmic (base 2) transformation was performed for the expression and non-canonical splicing data, which were analysed with the Cluster 3.0 (Clustering Library 1.5) program using the following parameters: similarity measures, absolute correlation decentralized and complete linkage method. Java TreeView 1.1.6r2 software was used to visualize the results.

\section{Results}

The expression of Ikaros interexonic regions in AIDs

When we analysed the expression of the Ikaros interexonic regions, significant differences were observed in regions IE2-3 $\left(x^{2}=16.5 ; p<0.01\right)$, IE3-4 $\left(x^{2}=17.1 ; p<0.01\right)$, IE4-5 $\left(x^{2}=32.8 ; p<0.0001\right)$ and IE6-7 $\left(x^{2}=30.8 ; p<0.0001\right)$. The Kruskal-Wallis analysis showed that there was a significant difference between at least two groups of comparisons in the expression level of each interexon, except for region IE5-6.

These results were confirmed by comparing each disease in pairs. The expression of IE2-3 was characteristic and significantly higher in RA patients compared to the other pathologies and controls (Fig. 2a). For IE3-4, individuals diagnosed with SLE had lower levels and individuals with RA had the highest expression levels of this region with respect to the controls and SLE and SS patients, and the differences were significant in both cases

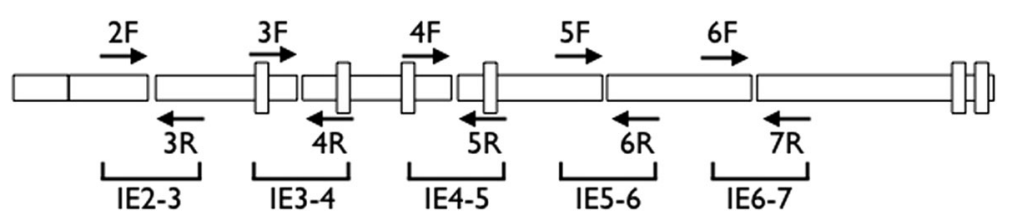

Fig. 1 Diagram of the location of the primers and the amplified regions in each PCR. Each PCR was designed between the final part of the preceding exon and the initial part of the next one. This design allows to avoid genomic contamination and also gives us information about the presence of non-canonical splicings 


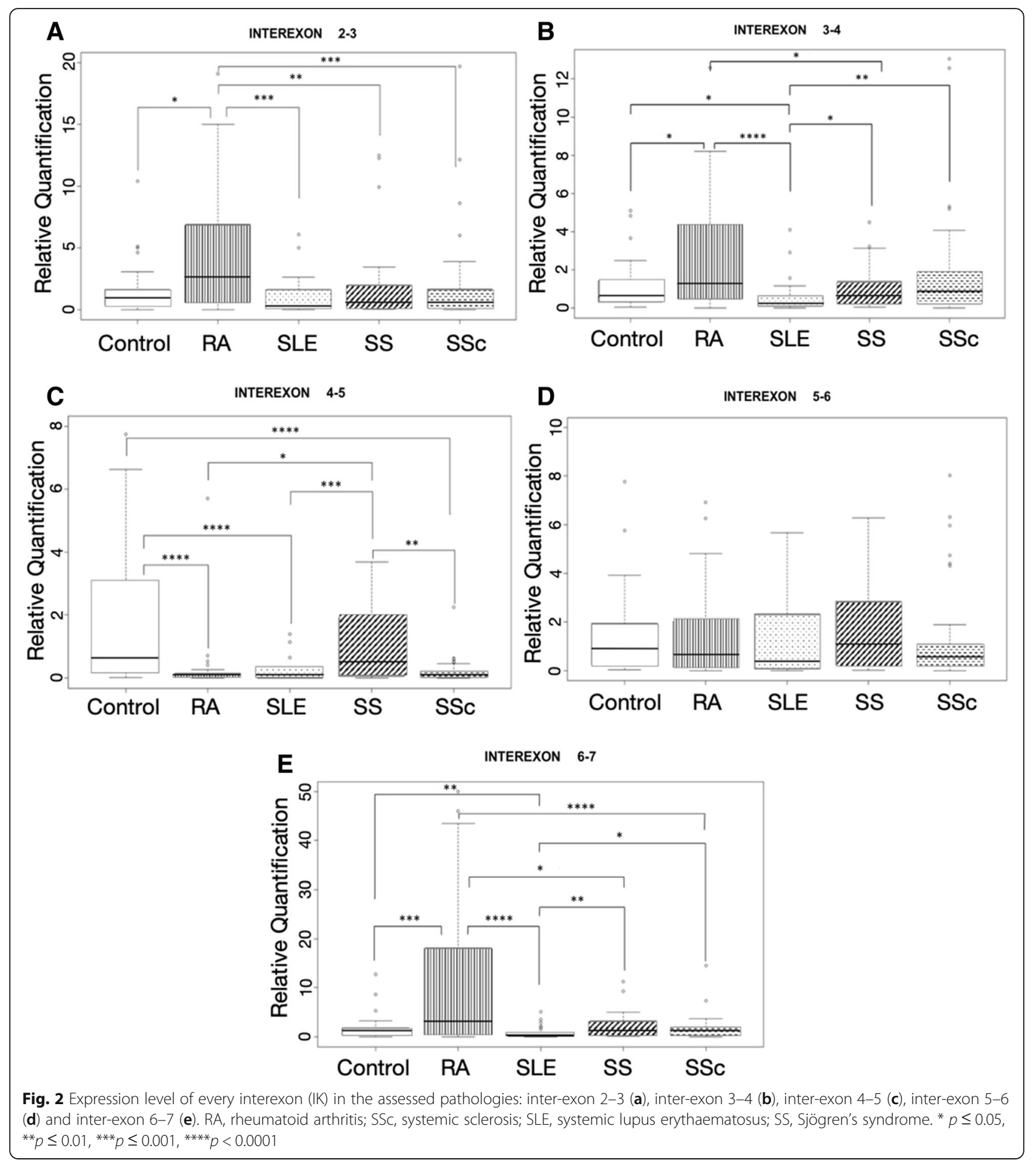

(Fig. 2b). No difference was found between the RA and SSc individuals.

For interexon 4-5, an important region for the DNA binding domain (DBD), we observed a higher expression level in the controls than in patients. This finding was related to the presence of $\mathrm{DN}$ isoforms with non-functional
DBDs. SS was the only disease that was not significantly different from the controls (Fig. 2c).

For interexonic region 5-6, similar expression levels were observed between all of the disease groups and the controls, indicating that this region may not be involved in these pathologies (Fig. 2d). 
For interexon 6-7, we found higher expression levels in individuals with RA and the lowest expression levels in SLE patients compared with other pathologies and controls, and the differences were significant in both cases (Fig. 2e), which may suggest that Ikaros has an altered the carboxyl terminus in patients with SLE that could affect its interaction with other proteins and/or transcription factors.

\section{Detection of splicing variants}

Detection of non-canonical splicing was performed by melting curve dissociation. Unlike in leukaemias [21], non-canonical splicing was frequent in the AIDs examined $(28 \%$ of the samples present non-canonical splicing). A curve of an interexonic region with two or more peaks indicates the presence of different amplicons or isoforms generated by non-canonical splicing, and we would thus expect certain insertions or deletions. In all of the pathologies, there were cases that showed two melting peaks for interexons IE2-3, IE3-4, IE5-6 and IE6-7, indicating the presence of isoforms with splicing variants for all of the Ikaros exons. In addition, we detected three melting peaks for IE2-3 in a patient with SS and for IE34 in 5 patients, 4 with RA and 1 with SSc, which suggests the existence of three possible isoform variants in these regions (Fig. 3 and Additional file 1: Table S1).

In rheumatoid arthritis and systemic Sclerosis patients, higher levels of isoforms (64.9\%) generated by non-canonical splicing were detected, with the majority of the variants occurring in interexons IE2-3 and IE3-4 (Fig. 3 and Additional file 1: Table S1). These variants involved exons encoding the DNA binding domain and, in

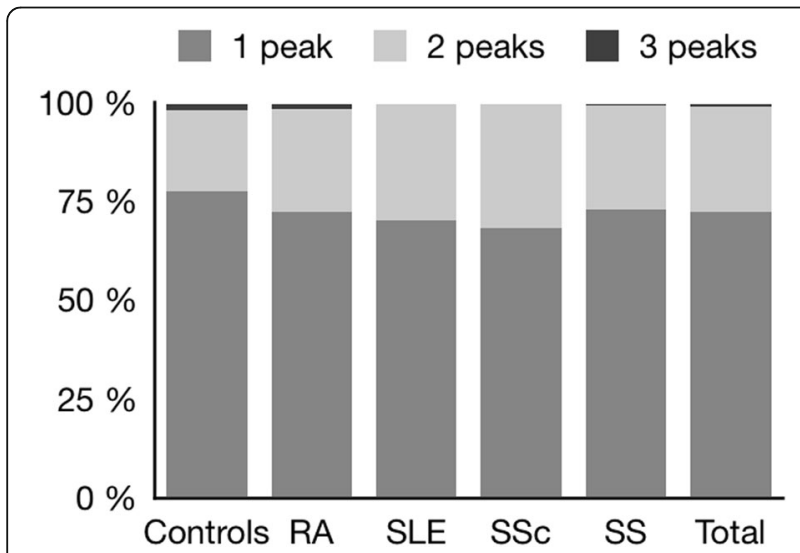

Fig. 3 Percentage of splicing variants detected in each exon. Most of the samples present canonic splicing ( $72 \%$ of all splicing). However, there is a $26 \%$ of cases in which two peaks are found. This phenomenon, with the standardized technique, is associated with the presence of non-canonical splicing. This percentage is especially important in the IE3-4, IE5-6 and IE6-7 regions. Triple peaks were also detected in a total of 10 samples (Additional file 1: Table S1) the case of splicing between exons 6 and 7, exons in the dimerization domain of the transcription factor, which may be relevant in these diseases.

The control group individuals also had more than one peak for all of the interexonic regions except for IE4-5, which mostly corresponded to IE2-3 (22 cases). Furthermore, three melting peaks were detected for IE3-4 in 4 control individuals (Fig. 3 and Additional file 1: Table S1). These splice variants may result in functional Ikaros isoforms for those observed in the 2-3 region; conversely, the IE3-4, IE5-6 and IE6-7 variants could be susceptibility variants, but the individuals who harbour them may not have developed a disease yet.

\section{Expression profile of each pathology}

The expression patterns of all of the Ikaros interexons were analysed together for the pathologies and for the control group. The control group had a very homogeneous profile with an equal proportion of expression for each region, mainly reflecting the presence of complete and functional isoforms. (Fig. 4a).

RA and SS patients had higher overall expression levels, which were accompanied by a higher proportion of DN isoforms. This presence of DN isoforms was especially important in RA, where a very characteristic profile was observed with exaggerated expression and the presence of isoforms lacking regions IE3-4, IE4-5 and IE5-6. Meanwhile, SLE and SSc individuals had lower overall expression and a more balanced profile, with a minimum of $\mathrm{DN}$ isoforms. SLE patients had the greatest presence of functional isoforms, indicating that lack of Ikaros expression may be the possible cause of this disease and not an imbalance of isoforms (Fig. 4a).

For a complete profile of Ikaros expression, the patients and controls were clustered, and the expression level of each interexonic region and the presence or absence of non-canonical splicing were considered. Although the disease groups could not be clearly differentiated from each other, three clusters were apparent (Fig. 4b). The first cluster comprised predominantly RA patients, who had higher expression levels of Ikaros and higher numbers of DN isoforms. The second group was characterized by homogeneous expression and was composed of the controls and the SSc and SS patients. The final cluster contained SLE samples, which had lower expression levels of Ikaros (Fig. 4b).

\section{Expression levels of Ikaros interexonic regions according to sex}

Given that autoimmune diseases are more common in women, we determined whether there were any differences between the expression levels of the distinct interexonic regions and the sex of the patients. The only 


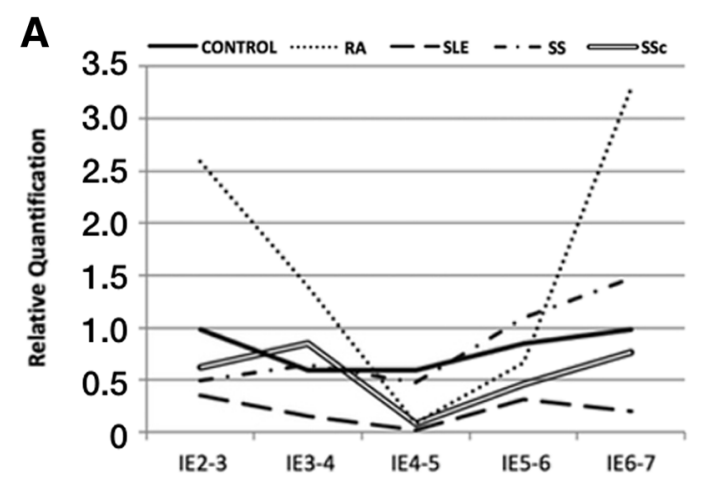

B

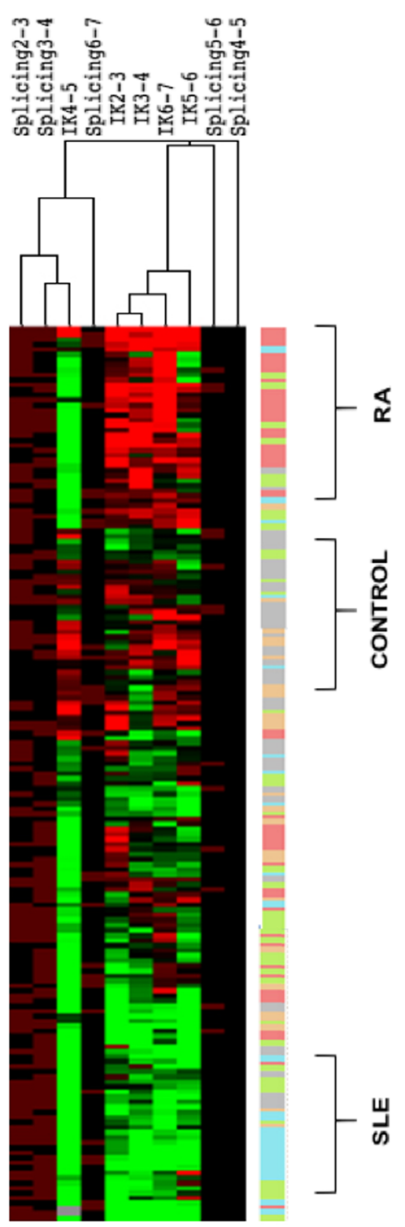

Fig. 4 Expression pattern and Hierarchical clustering of Ikaros in the assessed pathologies. (a) Expression pattern of Ikaros in the assessed pathologies: RA, rheumatoid arthritis; SSc, systemic sclerosis; SLE, systemic lupus erythaematosus; SS, Sjögren's syndrome. (b) Hierarchical clustering of Ikaros differential expression. Rows represent cases of RA, SLE, SS, SSC and controls, and columns refer to the $\log _{2}$ relative expression data and the absence or presence of non-canonical splicing. The expression levels are represented using a colour code with red and green corresponding to high and low expression, respectively, and the intensity refers to the magnitude of the deviation from the mean. The presence of non-canonical splicing is represented as "YES" and its absence as "NO"

significant difference in expression levels between the controls and patients with autoimmune diseases was in the IE4-5 region, which showed low expression in men and women with AIDs (Fig. 5 and Additional file 2: Figure S2).

The analysis by disease showed that expression levels were increased in men diagnosed with RA and SLE compared to women (Fig. 5a, b). The expression patterns of patients with SSc were similar, but women had higher expression levels. (Fig. 5c). The only significant differences in the expression levels according to sex were for IE2-3 in patients diagnosed with RA $(p=0.003)$ and for IE5-6 in patients with SLE $(p=0.026)$; no significant differences were found for individuals diagnosed with SSc. This analysis was not possible for the patients with SS as all of these individuals were female.

\section{Discussion}

This study is the first in Latin America to determine the relationship between Ikaros and autoimmune diseases using a different methodological approach. The expression of Ikaros, almost exclusively in lymphoid line in the peripheral blood, makes any kind of purification unnecessary and facilitates the implementation of this technique in a simple and effective way. The technique in the present study, which was standardized by Orozco et al. (2013) for haematological malignancies, showed that there were differences in the expression levels of Ikaros between individuals in the control group and those with different AID pathologies. Moreover, these differences were not only in terms of overall expression but also included clear differences in the distribution of isoforms in each of the diseases. These differences indicate that a 

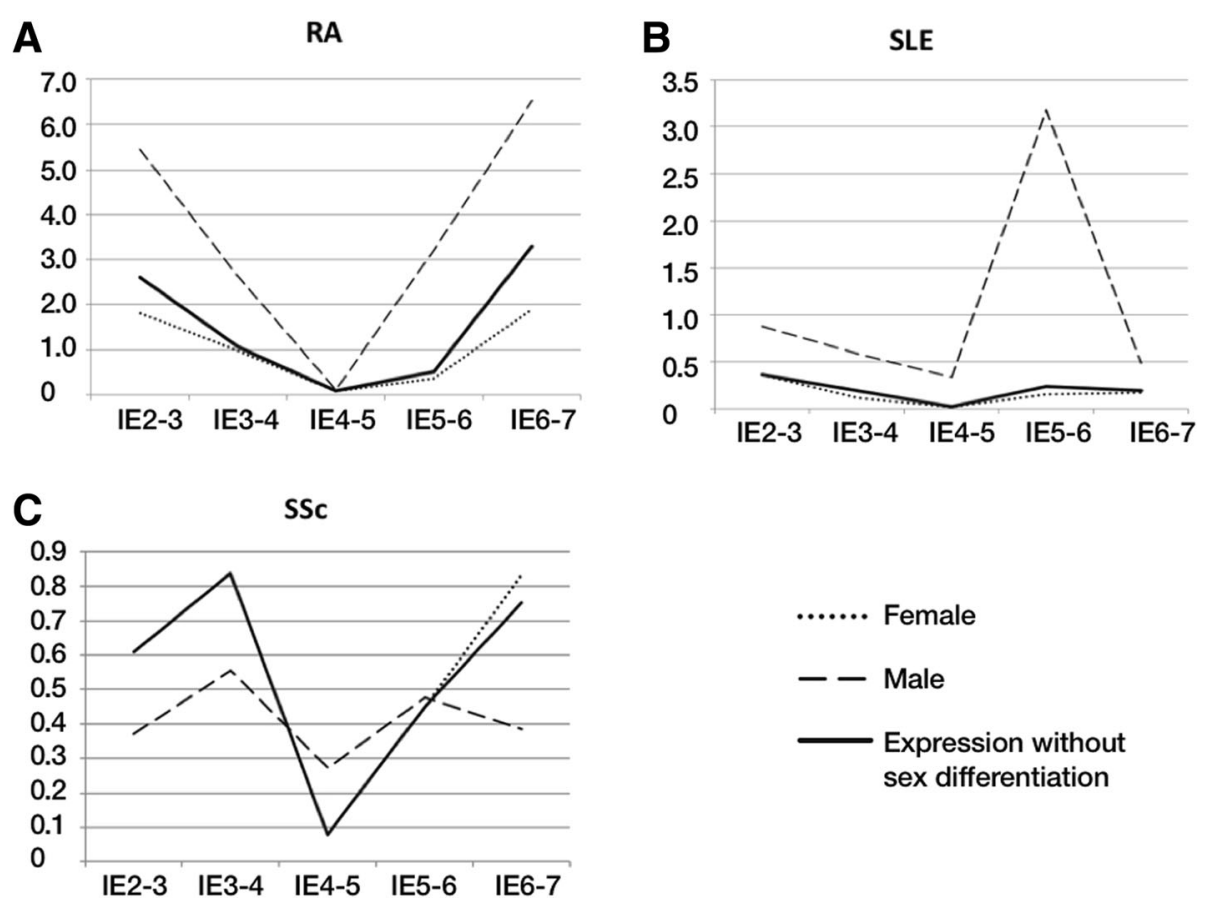

Fig. 5 Expression levels of Ikaros interexonic regions according to sex. Interexon expression in patients with rheumatoid arthritis (a), systemic lupus erythaematosus (b), and systemic sclerosis (c). The solid line shows the expression level without sex differentiation. F, female; M, male; RA, rheumatoid arthritis; SSc, systemic sclerosis; SLE, systemic lupus erythaematosus

specific Ikaros profile exists for each disease. Further studies are needed to define the role of Ikaros as a cause or effect of disease development, but our data clearly show its value as a biomarker for some of these diseases (Fig. 2 and Additional file 3: Figure S1).

In 2009, the Ikaros transcription factor was established as a new susceptibility gene for SLE through a GWAS study (Genome-wide association study) in a Chinese population, and it was identified as risk loci for Asian and Caucasian populations [34-39]. Before this study, there was no indication of the relationship between the Ikaros family and these diseases, although its role in lymphoid development made the connection somewhat plausible.

The methodology used in this study for the indirect quantification of isoforms has allowed us to corroborate alterations in the expression of Ikaros in SLE [40]. In this case, we not only confirmed that this disease is characterized by a low level of Ikaros expression but also demonstrated that, unlike other diseases, including haematological malignancies, there was not a significant presence of dominant negative isoforms in SLE. This difference may indicate that the molecular alteration is different and is based on promoter regulation, whereas the alternative splicing system seems to be altered in other diseases for reasons that are still unknown.

For other autoimmune diseases such as RA, SS and SSc, no association with Ikaros have been reported; thus, our study is the first to describe alterations in the expression of Ikaros. At this point, it should be noted that great differences were found in RA, and as IE3-4 or IE6-7 in SLE, the expression of IE2-3 or IE6-7 was sufficient to differentiate these diseases from the other diseases and the controls (Fig. 2 and Additional file 3: Figure S1).

The study of the IE4-5 region is particularly interesting in both autoimmune diseases and haematological tumours. This region is essential in the Ikaros protein structure because exons 4 and 5 contain three of the four zinc fingers motifs that comprise the DNA binding domain of the protein. For this reason, the lack of expression of this region is directly associated with the presence of dominant negative isoforms of Ikaros. The expression of a dominant negative isoform was characterized in murine models in a study by Wojcik et al. (2009) in which Ik-7 (DN) led to lymphocyte deregulation even in presence of functional isoforms, such as Ik-1 and Ik-3, resulting in a characteristic autoimmune disease phenotype. In this case, the decreased function of Ikaros and the presence of dominant negative isoforms on B cells did not result in leukaemia, likely due to activation of the Notch signalling pathway, which regulates $\mathrm{T}$ cell development and proliferation, in the presence of reduced Ikaros activity [41].

Our results showed a clear decrease in the expression of the IE4-5 region in all of the diseases; however, these results must be analysed in conjunction with those of the remaining exons. Thus, only the RA samples showed 
a clear presence of DN isoforms, while those of the SS and SSc patients were not substantially different from the controls. Conversely, the minimal expression of IE4-5 in individuals with SLE was associated with a general lack of expression and not the presence of DN isoforms (Fig. 4).

For the splicing variants, the two and three peak profiles detected in the IE2-3, IE3-4, IE5-6 and IE6-7 regions with the melting curve analysis indicated the presence of different non-canonical isoforms involving exons 3, 4 and 5 of the DNA binding domain, which could correspond to dominant negative isoforms (especially the IE3-4 variants). This non-canonical splicing could due to insertions and/or deletions that result in isoforms already known, such as IK1+ [13, 14], which has an insertion between exon 2 and 3, or IK1- [15], whose deletion at the $3^{\prime}$ end of exon 6 produces a truncated isoform. Moreover, variants in exons 6 and 7 could affect the domain that interacts with other proteins.

In control group individuals, the detected IE2-3 variants may be functional isoforms, as is the case with the single nucleotide variant ( $\mathrm{SNV}$ ) that harbours a change of $\mathrm{G}$ to $\mathrm{T}$ in position 501 (rs4917014) of the Ikaros DNA sequence and is considered a protector factor associated with IK-1 and IK-2 isoforms. The interaction of rs4917014 with other SNVs is believed to counteract its negative effects, reducing the risk of SLE [42]. IE3-4 and IE5-6 variants could be susceptibility variants, but the individuals who harbour them may not have developed an autoimmune disease yet or may not have demonstrated clear signs and symptoms of an AID yet. They may also correspond to SNVs that lead to non-germ constituent deletions of Ikaros exons 4 and 5, which have been previously reported in healthy populations [43], or Ikaros variants associated with other pathologies that have not been detected in these individuals, such as primary immunodeficiencies characterized by hypogammaglobulinemia and decreased B cell counts [43, 44]. In all of these cases, sequence-based studies that provide more detailed information about the insertions and/or deletions that occur in these diseases is needed.

Definitive conclusions could not be drawn regarding gene expression differences according to sex due to the low proportion of men in this study. However, curiously, the profiles of RA and SLE were clearly defined by one of the two sexes. For RA, men had profiles characterized by the high expression and abundance of $\mathrm{DN}$ isoforms; in SLE, women demonstrated a lack of total Ikaros expression with the disease. These findings are important because they indicate that including sex in any future nomogram that contains Ikaros as a predictive value of a disease is critical.

Although the role of Ikaros has been studied in cancer for a long time, for autoimmune diseases, data regarding the Aiolos gene are more prevalent. The deregulation of
Aiolos appears to cause autoimmune effects, which lead to the formation of autoreactive lymphocytes that can deleteriously affect the organism. Aiolos is normally expressed at high levels in mature B cells, and Aiolos-deficient adult mice developed glomerulonephritis mediated by immune complex formation in the kidney, which is characteristic of systemic lupus erythaematosus [45]. These mice had elevated serum levels of IgG and $\mathrm{IgE}$, and their B lymphocytes exhibited surface markers that indicate cellular activity and the spontaneous production of autoantibodies, such as anti-DNA, which are common in SLE [46].

The importance of Aiolos and Helios in the development of AIDs necessitates their inclusion in expression analyses, which will provide more information on the molecular mechanisms of these diseases and allow better discrimination between groups of pathologies, thus creating specific and complete expression profiles.

\section{Conclusion}

This study is the first conducted in Latinamerica that sought to determine the relationship between Ikaros and autoimmune diseases and is the first description of Ikaros in patients with rheumatoid arthritis, Sjögren's syndrome and systemic sclerosis. Furthermore, we confirmed that Ikaros expression is altered in systemic lupus erythaematosus. The use of interexonic PCR for the Ikaros gene allows the creation of distinctive expression profiles for some of the pathologies studied.

\section{Additional files}

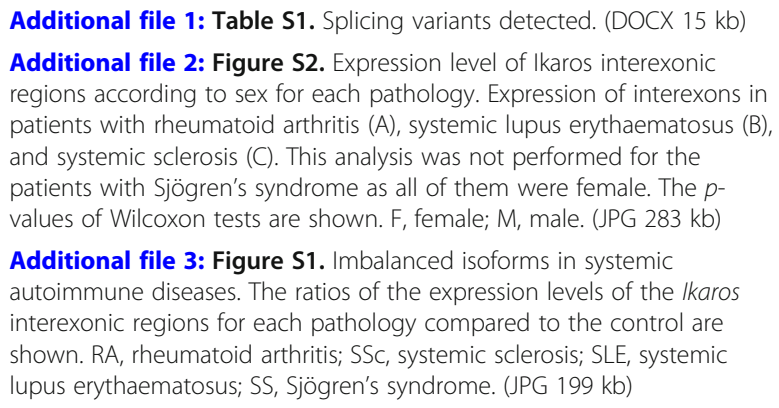

Additional file 3: Figure S1. Imbalanced isoforms in systemic autoimmune diseases. The ratios of the expression levels of the Ikaros interexonic regions for each pathology compared to the control are shown. RA, rheumatoid arthritis; SSc, systemic sclerosis; SLE, systemic lupus erythaematosus; SS, Sjögren's syndrome. (JPG 199 kb)

\footnotetext{
Abbreviations

AIDs: Autoimmune diseases; cDNA: Complementary deoxyribonucleic acid; Ct: Threshold cycle; CTLA4: Cytotoxic T-Lymphocyte Associated Protein 4; DNA: Deoxyribonucleic acid; GAPDH: Glyceraldehyde 3-phosphate dehydrogenase gene; HLA DR: Human Leukocyte Antigen - antigen D Related; IE: Interexonic Region; Ik: Ikaros; NCBI: National Center for Biotechnology Information; PAD4: Protein arginine deiminase 4; PTPN22: Protein tyrosine phosphatase, non-receptor type 22; qRT-PCR: Quantitative reverse transcription polymerase chain reaction; RA: Rheumatoid arthritis; RNA: Ribonucleic acid; SLE: Systemic lupus erythaematosus; SS: Sjögren's syndrome; SSc: Systemic sclerosis; STAT4): Signal transducer and activator of transcription 4; TRAF1 -C5: TNF receptor-associated factor 1 C5
} 


\section{Acknowledgments}

We would like to thank the patients, the Rheumatology Section of the Hospital Universitario Fundación Santa Fe de Bogotá (Colombia) for the samples and clinical support, and the School of Medicine of the Universidad de los Andes (Colombia) for funding this study

\section{Funding}

This study was funded by the School of Medicine of The Universidad de los Andes.

\section{Availability of data and materials}

Please contact author for data requests.

\section{Authors' contributions}

LKDS. Implementation and data collection, analysis and interpretation of the data, and writing of the paper. GQL. Samples recollection, analysis and interpretation of the data and critical review of the paper. PXCA. Samples recollection, analysis and interpretation of the data and critical review of the paper. PAMP. Samples recollection, analysis and interpretation of the data and critical review of the paper. GdRH. Analysis and interpretation of the data and Critical review of the paper. VLS. Conception and design of the study, database management, analysis and interpretation of the data, library search and assembly of relevant literature, and writing of the paper. All authors read and approved the final manuscript.

\section{Ethics approval and consent to participate}

The authors of this paper declare that both the Protocol and informed consent were approved by the University ethics committees (Comité de ética de la Universidad de los Andes) and by the Ethics Committee of the hospital that provided the samples (Comité de ética en investigación del Hospital Universitario Fundación Santa Fe de Bogotá). Likewise, patients who participated in the study were appropriately briefed and signed informed consent.

\section{Consent for publication}

All researchers give their permission for publication of this study.

\section{Competing interests}

The authors declare that they have no competing interests.

\section{Publisher's Note}

Springer Nature remains neutral with regard to jurisdictional claims in published maps and institutional affiliations.

\section{Author details \\ 'Human Genetics Laboratory, Universidad de los Andes, Bogotá, Colombia. ${ }^{2}$ School of Medicine, Universidad de los Andes, Cra. 1, №18 A 10, Building i, Office 112, Bogotá, Colombia. ${ }^{3}$ EAl-Reumavance Research Group, Hospital Universitario Fundación Santa Fe de Bogotá, Bogotá, Colombia.}

Received: 1 October 2018 Accepted: 28 November 2018 Published online: 14 December 2018

\section{References}

1. Anaya J-M, Corena R, Castiblanco J, et al. The kaleidoscope of autoimmunity: multiple autoimmune syndromes and familial autoimmunity. Expert Rev Clin Immunol. 2007;3:623-35. https://doi.org/10.1586/1744666X.3.4.623.

2. Cooper GS, Stroehla BC. The epidemiology of autoimmune diseases. Autoimmun Rev. 2003;2:119-25.

3. Sanchez-Rodriquez SH, Barajas-Vasquez GE, Ramirez-Alvarado ED, et al. Lupus eritematoso: enfermedad autoinmune sistémica y órgano específica. Biomed. 2004:1-8.

4. Pretel M, Marquès L, España A. Drug-induced lupus erythematosus. Actas Dermosifiliogr. 2014;105:18-30. https://doi.org/10.1016/j.ad.2012.09.007

5. Incorvaia E, Sicouri L, Petersen-Mahrt SK, Schmitz K-M. Hormones and AID: balancing immunity and autoimmunity. Autoimmunity. 2013;46:128-37. https://doi.org/10.3109/08916934.2012.748752

6. Pauklin S, Sernández IV, Bachmann G, et al. Estrogen directly activates AID transcription and function. J Exp Med. 2009;206:99-111. https://doi.org/10. 1084/jem.20080521.
7. Wellcome Trust Case Control Consortium, Australo-Anglo-American Spondylitis Consortium (TASC), Burton PR, et al. Association scan of 14,500 nonsynonymous SNPs in four diseases identifies autoimmunity variants. Nat Genet. 2007;39:1329-37. https://doi.org/10.1038/ng.2007.17.

8. Plenge RM, Seielstad M, Padyukov L, et al. TRAF1-C5 as a risk locus for rheumatoid arthritis--a genomewide study. 2007:357:1199-209. https://doi. org/10.1056/NEJMoa073491.

9. Perricone C, Ceccarelli F, Valesini G. An overview on the genetic of rheumatoid arthritis: a never-ending story. Autoimmun Rev. 2011;10:599608. https://doi.org/10.1016/j.autrev.2011.04.021.

10. Molnár A, Wu P, Largespada DA, et al. The Ikaros gene encodes a family of lymphocyte-restricted zinc finger DNA binding proteins, highly conserved in human and mouse. J Immunol. 1996:156:585-92.

11. John LB, Ward AC. The Ikaros gene family: transcriptional regulators of hematopoiesis and immunity. Mol Immunol. 2011;48:1272-8. https://doi. org/10.1016/j.molimm.2011.03.006.

12. Chrousos GP, Kino T. Ikaros transcription factors: flying between stress and inflammation. J Clin Invest. 2005;115:844-8. https://doi.org/10.1172/JCI24886.

13. Francis OL. Regulator of myeloid differentiation and function: the secret life of Ikaros. WJBC. 2011;2:119. https://doi.org/10.4331/wjbc.v2.i6.119.

14. Capece D, Zazzeroni F, Mancarelli MM, et al. A novel, non-canonical splice variant of the Ikaros gene is aberrantly expressed in B-cell lymphoproliferative disorders. PLoS One. 2013;8:e68080-13. https://doi.org/ 10.1371/journal.pone.0068080.

15. Payne KJ, Huang G, Sahakian $\mathrm{E}$, et al. Ikaros isoform $\mathrm{x}$ is selectively expressed in myeloid differentiation. J Immunol. 2003;170:3091-8.

16. Nakase K, Ishimaru F, Fujii K, et al. Overexpression of novel short isoforms of Helios in a patient with T-cell acute lymphoblastic leukemia. Exp Hematol. 2002;30:313-7.

17. lacobucci I, Lonetti A, Messa F, et al. Expression of spliced oncogenic Ikaros isoforms in Philadelphia-positive acute lymphoblastic leukemia patients treated with tyrosine kinase inhibitors: implications for .... Am Soc Hematology. https://doi.org/10.1182/blood-2007.

18. Rebollo A, Schmitt C. Ikaros, Aiolos and Helios: transcription regulators and lymphoid malignancies. Immunol Cell Biol. 2003;81:171-5. https://doi.org/10. 1046/j.1440-1711.2003.01159.x.

19. Georgopoulos K. Haematopoietic cell-fate decisions, chromatin regulation and ikaros. Nat Rev Immunol. 2002;2:162-74. https://doi.org/10.1038/nri747.

20. Nakase $\mathrm{K}$, Ishimaru F, Avitahl N, et al. Dominant negative isoform of the Ikaros gene in patients with adult B-cell acute lymphoblastic leukemia. Cancer Res. 2000;60:4062-5.

21. Orozco CA, Acevedo A, Cortina L, et al. The combined expression patterns of Ikaros isoforms characterize different hematological tumor subtypes. PLoS One. 2013;8:e82411. https://doi.org/10.1371/journal.pone.0082411.s002.

22. Theocharides APA, Dobson SM, Laurenti E, et al. Dominant-negative Ikaros cooperates with BCR-ABL1 to induce human acute myeloid leukemia in xenografts. Leukemia. 2015;29:177-87. https://doi.org/10.1038/leu.2014.150.

23. Movassagh $M$, Laderach $D$, Galy A. Proteins of the Ikaros family control dendritic cell maturation required to induce optimal Th1 T cell differentiation. Int Immunol. 2004;16:867-75. https://doi.org/10.1093/intimm/dxh090.

24. Watford WT, Hissong BD, Bream JH, et al. Signaling by IL-12 and IL-23 and the immunoregulatory roles of STAT4. Immunol Rev. 2004;202:139-56. https://doi.org/10.1111/j.0105-2896.2004.00211.x.

25. Yap W-H, Yeoh E, Tay A, et al. STAT4 is a target of the hematopoietic zincfinger transcription factor Ikaros in T cells. FEBS Lett. 2005;579:4470-8. https://doi.org/10.1016/j.febslet.2005.07.018.

26. Nakayama $\mathrm{H}$, Ishimaru $\mathrm{F}$, Avitahl N, et al. Decreases in Ikaros activity correlate with blast crisis in patients with chronic myelogenous leukemia. Cancer Res. 1999;59:3931-4.

27. Ruiz A, Jiang J, Kempski H, Brady HJM. Overexpression of the Ikaros 6 isoform is restricted to $t(4 ; 11)$ acute lymphoblastic leukaemia in children and infants and has a role in B-cell survival. Br J Haematol. 2004:125:31-7.

28. Mullighan CG, Miller CB, Radtke I, et al. BCR-ABL1 lymphoblastic leukaemia is characterized by the deletion of Ikaros. Nature. 2008:453:110-4. https://doi. org/10.1038/nature06866.

29. Iacobucci I, Lonetti A, Cilloni D, et al. Identification of different Ikaros CDNA transcripts in Philadelphia-positive adult acute lymphoblastic leukemia by a high-throughput capillary electrophoresis sizing method. Haematologica. 2008:93:1814-21. https://doi.org/10.3324/haematol.13260.

30. Bustin SA, Benes V, Garson JA, et al. The MIQE guidelines: minimum information for publication of quantitative real-time PCR experiments. Clin Chem. 2009;55:611-22. https://doi.org/10.1373/clinchem.2008.112797. 
31. Taylor S, Wakem M, Dijkman G, et al. A practical approach to RT-qPCRpublishing data that conform to the MIQE guidelines. METHODS. 2010;50: S1-5. https://doi.org/10.1016/j.ymeth.2010.01.005.

32. Pfaffl MW. A new mathematical model for relative quantification in real-time RT-PCR. Nucleic Acids Res. 2001;29:e45.

33. Pfaffl MW, Horgan GW, Dempfle L. Relative expression software tool (REST) for group-wise comparison and statistical analysis of relative expression results in real-time PCR. Nucleic Acids Res. 2002;30:e36.

34. Han J-W, Zheng H-F, Cui Y, et al. Genome-wide association study in a Chinese Han population identifies nine new susceptibility loci for systemic lupus erythematosus. Nat Genet. 2009:41:1234-7. https://doi.org/10.1038/ng.472.

35. Cunninghame Graham DS, Morris DL, Bhangale TR, et al. Association of NCF2, IKZF1, IRF8, IFIH1, and TYK2 with systemic lupus erythematosus. PLoS Genet. 2011;7:e1002341. https://doi.org/10.1371/journal.pgen.1002341.

36. Wang C, Ahlford A, Järvinen TM, et al. Genes identified in Asian SLE GWASS are also associated with SLE in Caucasian populations. Eur J Hum Genet. 2013;21:994-9. https://doi.org/10.1038/ejhg.2012.277.

37. Lee H-S, Kim T, Bang SY, et al. Ethnic specificity of lupus-associated loci identified in a genome-wide association study in Korean women. Ann Rheum Dis. 2014;73:1240-5. https://doi.org/10.1136/annrheumdis-2012202675.

38. Bentham J, Morris DL, Graham DSC, et al. Genetic association analyses implicate aberrant regulation of innate and adaptive immunity genes in the pathogenesis of systemic lupus erythematosus. Nat Genet. 2015;47:1457-64. https://doi.org/10.1038/ng.3434.

39. You Y, Zhai ZF, Chen FR, et al. Autoimmune risk loci of IL12RB2, IKZF1, XKR6, TMEM39A and CSK in Chinese patients with systemic lupus erythematosus. Tissue Antigens. 2015;85:200-3. https://doi.org/10.1111/tan.12522.

40. Hu W, Sun L, Gao J, et al. Down-regulated expression of IKZF1 mRNA in peripheral blood mononuclear cells from patients with systemic lupus erythematosus. Rheumatol Int. 2010;31:819-22. https://doi.org/10.1007/ s00296-010-1576-1.

41. Wojcik H, Griffiths E, Staggs S, et al. Expression of a non-DNA-binding Ikaros isoform exclusively in B cells leads to autoimmunity but not leukemogenesis. Eur J Immunol. 2007;37:1022-32. https://doi.org/10.1002/ eji.200637026.

42. Dang J, Shan S, Li J, et al. Gene-gene interactions of IRF5, STAT4, IKZF1 and ETS1 in systemic lupus erythematosus. Tissue Antigens. 2014;83:401-8. https://doi.org/10.1111/tan.12349.

43. Kuehn HS, Boisson B, Cunningham-Rundles $C$, et al. Loss of B cells in patients with heterozygous mutations in IKAROS. N Engl J Med. 2016;374: 1032-43. https://doi.org/10.1056/NEJMoa1512234.

44. Al-Herz W, Bousfiha A, Casanova J-L, et al. Primary immunodeficiency diseases: an update on the classification from the international union of immunological societies expert committee for primary immunodeficiency. Front Immunol. 2014;5:162. https://doi.org/10.3389/fimmu.2014.00162.

45. Sun J, Matthias G, Mihatsch MJ, et al. Lack of the transcriptional coactivator OBF-1 prevents the development of systemic lupus erythematosus-like phenotypes in Aiolos mutant mice. J Immunol. 2003;170:1699-706.

46. Cai X, Qiao Y, Diao C, et al. Association between polymorphisms of the IKZF3 gene and systemic lupus erythematosus in a Chinese Han population. PLoS One. 2014;9:e108661. https://doi.org/10.1371/journal.pone.0108661.

\section{Ready to submit your research? Choose BMC and benefit from:}

- fast, convenient online submission

- thorough peer review by experienced researchers in your field

- rapid publication on acceptance

- support for research data, including large and complex data types

- gold Open Access which fosters wider collaboration and increased citations

- maximum visibility for your research: over $100 \mathrm{M}$ website views per year

At BMC, research is always in progress.

Learn more biomedcentral.com/submissions 